\title{
Redox Dual-Cocatalyst-Modified CdS Double-Heterojunction Photocatalysts for Efficient Hydrogen Production
}

\author{
Yi Zhao, Yongfeng Lu, Lu Chen, Xiaofeng Wei, Jiefang Zhu,* and Yuanhui Zheng*
}

Cite This: ACS Appl. Mater. Interfaces 2020, 12, 46073-46083

Read Online

ABSTRACT: Cadmium sulfide ( $\mathrm{CdS}$ ) as one of the most common visible-lightresponsive photocatalysts has been widely investigated for hydrogen generation. However, its low solar-hydrogen conversion efficiency caused by fast carrier recombination and poor catalytic activity hinders its practical applications. To address this issue, we develop a novel and highly efficient nickel-cobalt phosphide and phosphate cocatalyst-modified $\mathrm{CdS}(\mathrm{NiCoP} / \mathrm{CdS} / \mathrm{NiCoPi})$ photocatalyst for hydrogen evolution. The dual-cocatalysts were simultaneously deposited on CdS during one phosphating step by using sodium hypophosphate as the phosphorus source. After the loading of the dual-cocatalysts, the photocurrent of CdS significantly increased, while its electrical impedance and photoluminescence emission dramatically decreased, which indicates the enhancement of charge carrier separation. It was proposed that the $\mathrm{NiCoP}$ cocatalyst accepts electrons and promotes hydrogen evolution, while the $\mathrm{NiCoPi}$ cocatalyst donates electrons

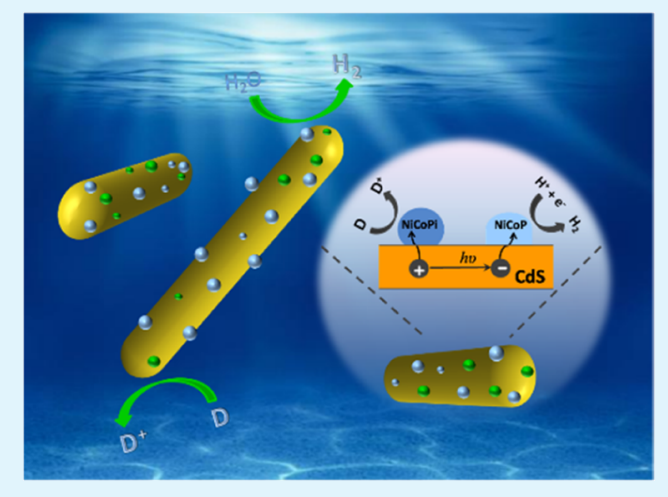
and accelerates the oxidation of sacrificial agents (e.g., lactic acid). Consequently, the visible-light-driven hydrogen evolution of this composite photocatalyst greatly improved. The dual-cocatalyst-modified CdS with a loading content of $5 \mathrm{~mol} \%$ showed a high hydrogen evolution rate of $80.8 \mathrm{mmol} \cdot \mathrm{g}^{-1} \cdot \mathrm{h}^{-1}$, which was 202 times higher than that of bare CdS $\left(0.4 \mathrm{mmol} \cdot \mathrm{g}^{-1} \cdot \mathrm{h}^{-1}\right)$. This is the highest enhancement factor for metal phosphide-modified CdS photocatalysts. It also exhibited remarkable stability in a continuous photocatalytic test with a total reaction time of $24 \mathrm{~h}$.

KEYWORDS: cadmium sulfide, phosphide, phosphate, double heterojunctions, photocatalytic hydrogen evolution

\section{INTRODUCTION}

Using semiconductor materials to directly convert solar energy into hydrogen energy is regarded as a promising approach to the storage of renewable energy. ${ }^{1-3}$ The practical application of this technology requires the design and development of lowcost and highly active photocatalysts, which usually consist of a semiconductor as a solar light absorber and a noble metal (e.g., gold, platinum, or palladium) as a hydrogen evolution cocatalyst. $^{4-6}$ During the photocatalytic process, the semiconductor harvests and converts solar light and generates electron-hole pairs (i.e., charge carriers) that can be spatially separated by the in-built electric field at the metal-semiconductor heterojunction. ${ }^{2}$ The electrons migrating to the noble metal cocatalyst are eventually captured by the protons adsorbed on its surface, while the holes remaining in the semiconductor oxidize sacrificial reagents in the aqueous solution. Regarding the selection of semiconductor photocatalysts, cadmium sulfide $(\mathrm{CdS})$ is considered as a model candidate because of its desirable bandgap $\left(E_{\mathrm{g}} \approx 2.4 \mathrm{eV}\right)$ for visible-light-driven photocatalysis and appropriate band-edge potentials for water splitting. ${ }^{7,8}$ However, like other semiconductors, pure CdS suffers from extremely low solarhydrogen conversion efficiency, because of its low chargeseparation efficiency and poor catalytic activity toward water reduction. ${ }^{9}$ As to the choice of hydrogen evolution cocatalysts, earth-abundant transition metal compounds, such as metal oxides, ${ }^{10-12}$ metal sulfides, ${ }^{13-16}$ metal carbides, ${ }^{17-19}$ metal nitrides, $^{20-22}$ and metal phosphides (MP), ${ }^{23-29}$ that have relatively high mechanical strength, electrical conductivity, and chemical stability, have been explored as promising alternatives to noble-metal cocatalysts.

Metal phosphorus compounds, including MP and metal phosphates (MPi), have been widely used as hydrogen evolution reaction (HER) cocatalysts. ${ }^{23-39}$ Recently, transition MPs with a large number of unsaturated coordination surface atoms have attracted particular attention in photocatalytic hydrogen evolution. ${ }^{23-33} \mathrm{Liu}$ and Rodriguez theoretically predicted that nickel phosphide $\left(\mathrm{Ni}_{2} \mathrm{P}\right)$ might be the best practical cocatalyst for hydrogen evolution. ${ }^{40}$ So far, many MPs, such as $\mathrm{Ni}_{2} \mathrm{P},{ }^{28} \mathrm{CoP},{ }^{23,24} \mathrm{FeP},{ }^{25,26} \mathrm{Cu}_{3} \mathrm{P},{ }^{27}$ and $\mathrm{MoP},{ }^{29}$ have been fabricated and coupled with $\mathrm{CdS}$ as hydrogen

Received: July 15, 2020

Accepted: September 15, 2020

Published: September 15, 2020 
evolution cocatalysts. Their photocatalytic activity was typically 4-67 times higher than that of bare CdS (see more comparison details in Table S1). ${ }^{23-29}$ Further improvement of photocatalytic activity requires the codeposition of an oxidation cocatalyst that facilitates the hole scavenging. ${ }^{41}$ Metal phosphates (MPi), which have open-framework structures with large channels and cavities, have been proved to be good water oxidation catalysts in the electrocatalytic oxygen evolution reaction. Therefore, metal phosphates (MPi) can be used as oxidation cocatalysts in photocatalysis.

It has recently been demonstrated that a double-heterojunction photocatalytic system containing both reduction and oxidation cocatalysts exhibited better photocatalytic hydrogen evolution performance than their single-cocatalyst counterparts. $^{42-45}$ For example, Yang et al. reported a dual-cocatalyst $\mathrm{Pt} / \mathrm{CdS} / \mathrm{PdS}$ system with $\mathrm{Pt}$ and $\mathrm{PdS}$ as reduction and oxidation cocatalysts, respectively, which showed activity 1.76 times higher than that of $\mathrm{Pt} / \mathrm{CdS}{ }^{42}$ More recently, Wei et al. developed a new dual-cocatalyst system by replacing precious metal-containing redox cocatalysts with low-cost carbon dots and NiS, which exhibited 5.4 time activity enhancement, compared with pristine CdS. ${ }^{44}$

Despite some impressive progress in the development of dual-cocatalyst containing photocatalysts, a general drawback of the existing systems is that they require a stepwise loading for dual-cocatalyst modification and often suffer from a low catalytic activity enhancement. ${ }^{42}$ To address these issues, we explore a new synthetic route that can simultaneously generate oxidation and reduction cocatalysts in a one-step phosphating reaction and achieve a highly efficient dual-cocatalyst-modified $\mathrm{CdS}$ photocatalyst, NiCoP/CdS/NiCoPi. The NiCoP-NiCoPi dual cocatalysts were deposited on $\mathrm{CdS}$ nanorods via a bimetal nickel-cobalt hydroxide precursor reacting with the volatile decomposition products from sodium hypophosphate at 300 ${ }^{\circ} \mathrm{C}$ and at a low flow rate of the inert carrier gas. The obtained $\mathrm{NiCoP} / \mathrm{CdS} / \mathrm{NiCoPi}$ double heterojunctions were characterized by transmission electron microscopy (TEM), X-ray photoelectron spectroscopy (XPS), and Fourier transform infrared (FTIR) spectroscopy. The visible-light-driven hydrogen production by $\mathrm{NiCoP} / \mathrm{CdS} / \mathrm{NiCoPi}$ was tested and compared with $\mathrm{CdS}$ and $\mathrm{Pt} / \mathrm{CdS}$ as references. The optimal loading content of the cocatalysts was found to be $5 \mathrm{~mol} \%$. The resulting photocatalyst showed a hydrogen evolution rate of $80.8 \mathrm{mmol} \cdot \mathrm{g}^{-1} \cdot \mathrm{h}^{-1}$ under visible light irradiation $(>420 \mathrm{~nm})$, 202 times and 17 times higher than those of pristine CdS ( 0.4 $\left.\mathrm{mmol} \cdot \mathrm{g}^{-1} \cdot \mathrm{h}^{-1}\right)$ and $\mathrm{Pt} / \mathrm{CdS}\left(7.6 \mathrm{mmol} \cdot \mathrm{g}^{-1} \cdot \mathrm{h}^{-1}\right)$, respectively.

\section{EXPERIMENT}

2.1. Materials and Chemicals. All chemicals were of analytical grade, obtained from commercial suppliers and used without further purification. Cobalt(II) nitrate hexahydrate $\left(\mathrm{Co}\left(\mathrm{NO}_{3}\right)_{2} \cdot 6 \mathrm{H}_{2} \mathrm{O}\right)$, nickel(II) nitrate hexahydrate $\left(\mathrm{Ni}\left(\mathrm{NO}_{3}\right)_{2}\right.$. $\left.6 \mathrm{H}_{2} \mathrm{O}\right)$, urea $\left(\mathrm{H}_{2} \mathrm{NCONH}_{2}\right)$, ethylenediamine $\left(\mathrm{C}_{2} \mathrm{H}_{8} \mathrm{~N}_{2}\right)$, ammonium fluoride $\left(\mathrm{NH}_{4} \mathrm{~F}\right)$, and thiourea $\left(\mathrm{NH}_{2} \mathrm{CSNH}_{2}\right)$ were purchased from Sinopharm Chemical Reagent Co., Ltd (China). Lactic acid, cadmium chloride hemipentahydrate $\left(\mathrm{CdCl}_{2} \cdot 2.5 \mathrm{H}_{2} \mathrm{O}\right)$, and sodium hypophosphite $\left(\mathrm{NaH}_{2} \mathrm{PO}_{2}\right)$ were purchased from Aladdin.

2.2. Catalyst Preparation. 2.2.1. Preparation of $C d S$ Photocatalysts. CdS was prepared via a reported method. ${ }^{46}$ In a typical procedure, cadmium chloride hemi-pentahydrate and thiourea (molar ratio $=1: 3$ ) were put into $60 \mathrm{~mL}$ of ethylenediamine with continuous stirring for $30 \mathrm{~min}$. Having been completely dissolved, the mixture was transferred to a $100 \mathrm{~mL}$ Teflon-lined stainless steel autoclave and treated at $160{ }^{\circ} \mathrm{C}$ for $48 \mathrm{~h}$. After cooling, the resulting yellow product was washed with distilled water and ethanol, and collected via centrifugation at $5000 \mathrm{rpm}$ (Shanghai Anting, TDL-5-A). Then, the powder was dried at room temperature.

2.2.2. Preparation of NiCoP/CdS/NiCoPi Photocatalysts. $500 \mathrm{mg}$ of as-synthesized $\mathrm{CdS}$ was added to $60 \mathrm{~mL}$ of deionized water containing cobalt(II) nitrate hexahydrate, nickel(II) nitrate hexahydrate, urea, and $\mathrm{NH}_{4} \mathrm{~F}$ with a molar ratio of $1: 1: 10: 5$. Then, the mixed solution was treated in a 100 $\mathrm{mL}$ Teflon-lined stainless steel autoclave at $120{ }^{\circ} \mathrm{C}$ for $10 \mathrm{~h}$. The product was collected via centrifugation, washed by distilled water, and dried in vacuum at $60{ }^{\circ} \mathrm{C}$ to obtain the $\mathrm{CdS} / \mathrm{NiCo}(\mathrm{OH})_{x}$ precursor. Finally, the obtained CdS/ $\mathrm{NiCo}(\mathrm{OH})_{x}$ and an appropriate amount of $\mathrm{NaH}_{2} \mathrm{PO}_{2}$ (molar ratio $=1: 10$ ) were separately placed in two porcelain boats with $\mathrm{NaH}_{2} \mathrm{PO}_{2}$ upstream in the furnace, and treated at $300{ }^{\circ} \mathrm{C}$ for $2 \mathrm{~h}$ under $10 \mathrm{~mL} \cdot \mathrm{min}^{-1}$ nitrogen flow. By adjusting the amount of nickel-cobalt precursor, $\mathrm{NiCoP} / \mathrm{CdS} / \mathrm{NiCoPi}$ photocatalysts with a $\mathrm{NiCoP}-\mathrm{NiCoPi}$ theoretic loading contents of 1, 3, 5, 7, and $9 \mathrm{~mol} \%$ were prepared. For comparison, two reference samples (i.e., $\mathrm{NiCoP} / \mathrm{CdS}$ and $\mathrm{NiCoPi} / \mathrm{CdS}$ ) were prepared via the reported methods. The $\mathrm{NiCoPi} / \mathrm{CdS}$ photocatalyst was prepared by changing the flow rate of carrier gas to $40 \mathrm{~mL} / \mathrm{min}$. Meanwhile, the $\mathrm{NiCoP} / \mathrm{CdS}$ photocatalyst was fabricated via slight modification of the method reported by Shi and Shen ${ }^{37}$ Specifically, $500 \mathrm{mg}$ of the obtained $\mathrm{CdS} / \mathrm{NiCo}(\mathrm{OH})_{x}$ and $300 \mathrm{mg}$ of $\mathrm{NaH}_{2} \mathrm{PO}_{2}$ were separately placed in two porcelain boats with $\mathrm{NaH}_{2} \mathrm{PO}_{2}$ upstream in the furnace, and treated at $150{ }^{\circ} \mathrm{C}$ for $2 \mathrm{~h}$ under $10 \mathrm{~mL} \cdot \mathrm{min}^{-1}$ nitrogen stream.

2.3. Catalyst Characterization. Powder X-ray diffraction (XRD) patterns of the as-prepared photocatalysts were recorded with a Bruker D8 ADVANCE X-ray diffractometer using $\mathrm{Cu} \mathrm{K} \alpha$ radiation. The morphology and microstructure were studied using a high-resolution transmission electron microscope (Tecnai model G2 F20 S-TWIN). Meanwhile, an energy-dispersive spectroscope attached to the TEM instrument was applied to perform elemental mapping of the catalysts. XPS analysis was performed on a VG ESCALAB 250 spectrometer using a monochromatic $\mathrm{Al} \mathrm{K} \alpha \mathrm{X}$-ray. FTIR spectroscopy was analyzed with a FTIR spectrometer (Nicolet iS50, Thermo Fisher Scientific). The optical absorption of the samples was measured by a UV-vis diffuse reflectance spectrophotometer (Cary 500, Varian Co.) using $\mathrm{BaSO}_{4}$ as a reflectance. Photoluminescence (PL) was examined with a FL/ FS 920 TCSPC fluorescence spectrophotometer at an excitation wavelength of $420 \mathrm{~nm}$.

2.4. Photoelectrochemical (PEC) Measurements. PEC measurements were performed on a CHI1030B electrochemical workstation using a conventional three-electrode cell with a $\mathrm{Ag} / \mathrm{AgCl}$ reference electrode, a Pt counter electrode, and a prepared working electrode. To fabricate working electrodes, $10 \mu \mathrm{L}$ of $10 \mathrm{mg} \cdot \mathrm{mL}^{-1}$ photocatalyst slurry (in dimethylformamide) was dropped onto a FTO substrate and then dried in air. Photocurrents were measured in the $\mathrm{Na}_{2} \mathrm{SO}_{4}$ $(0.5 \mathrm{M})$ electrolyte solution using a $300 \mathrm{~W}$ xenon lamp with a band-cutoff filter $(420 \mathrm{~nm})$ as the light source. Electrochemical impedance spectroscopy (EIS) was measured over a frequency range from 0.01 to $10^{5}$ at an applied potential of $0.5 \mathrm{~V}$ using 10 $\mathrm{mM} \mathrm{K}_{3}\left[\mathrm{Fe}(\mathrm{CN})_{6}\right] / \mathrm{K}_{4}\left[\mathrm{Fe}(\mathrm{CN})_{6}\right]$ aqueous solution as the electrolyte. 
2.5. Photocatalytic Hydrogen Evolution. Photocatalytic hydrogen evolution was carried out in a Pyrex cell in a top irradiation mode, and the cell was connected to a closed gas circulation and evacuation system (Perfectlight, Beijing, China). In a typical process, the catalyst $(5 \mathrm{mg})$ was dispersed in $100 \mathrm{~mL}$ of the aqueous solution containing $10 \mathrm{vol} \%$ lactic acid as the sacrificial reagent with continuous stirring. Before the reaction, the system was sealed and vacuumed for $30 \mathrm{~min}$. Then, the system was irradiated with a $300 \mathrm{~W}$ xenon lamp equipped with a band-cutoff filter $(420 \mathrm{~nm})$. The amount of evolved hydrogen was monitored using an in situ gas chromatograph (FULI, GC9790, TCD detector, China) with a thermal conductivity detector. Apparent quantum efficiency (AQE) was measured under different wavelength irradiation using band-pass filters (Pyrex, 420-600 nm), and calculated using follow equations (eq 1)

$$
\begin{aligned}
& \operatorname{AQE}(\%)=\frac{\text { number of reacted electrons }}{\text { number of incident photons }} \times 100 \% \\
& =\frac{\text { number of evolved } \mathrm{H}_{2} \text { molecules } \times 2}{\text { number of incident photons }} \times 100 \%
\end{aligned}
$$

\section{RESULTS AND DISCUSSION}

It has previously been reported that sodium hypophosphite can decompose into low valence state products (e.g., phosphine and phosphorus) and high valence state products (e.g., pyrophosphates, phosphates, and metaphosphates) at an elevated temperature of $\geq 150{ }^{\circ} \mathrm{C}$ via disproportionation reactions. ${ }^{37}$ The thermal decomposition products readily react with transition metal oxides or hydroxides, forming MP and MPi. Shi et al. showed that pure MP only formed in a reaction temperature range of $150-200{ }^{\circ} \mathrm{C}$ and/or at a high molar ratio $(\geq 3)$ of hypophosphate to metal precursor. ${ }^{34,37}$ However, at a higher temperature $\left(\geq 250{ }^{\circ} \mathrm{C}\right)$ or a lower [hypophosphate]/[metal precursor] ratio, a mixture of $\mathrm{MP}$ and MPi was obtained. The higher the reaction temperature was, the more MPi was present. Recently, when we applied this method to the synthesis of NiCoP-decorated CdS photocatalysts, the flow rate of the inert carrier gas had a key impact on the final products, and only $\mathrm{NiCoPi}$ was obtained at $300{ }^{\circ} \mathrm{C}$ with a nitrogen flow rate of $40 \mathrm{~mL} \cdot \mathrm{min}^{-1.34}$ It is generally accepted that sodium hypophosphate initially decomposes into phosphine (gas) and disodium hydrogen phosphate (melting point: $\sim 250{ }^{\circ} \mathrm{C}$ ) at $300^{\circ} \mathrm{C}$ in an inert atmosphere through the following reaction

The generated phosphine gas in eq 2 is swept away by the inert carrier gas without participation in any reaction, while the

$$
2 \mathrm{NaH}_{2} \mathrm{PO}_{2} \stackrel{\triangleq}{=} \mathrm{Na}_{2} \mathrm{HPO}_{4}+\mathrm{PH}_{3} \uparrow \text { (eqn.2) }
$$

disodium hydrogen phosphate vapor (whose mobility is much slower than that of phosphine gas) reacts with the metal oxide or hydroxide precursors, forming $\mathrm{MPi} .{ }^{34}$ It is easy for disodium hydrogen phosphate to evaporate at a temperature higher than its melting point. This also explains the observation of MP only at a low reaction temperature $\left(150-200{ }^{\circ} \mathrm{C}\right)$ and $\mathrm{MPi}$ at a high reaction temperature $\left(\geq 250^{\circ} \mathrm{C}\right)$. That is to say, by tuning the reaction temperature and the flow rate of carrier gas, simultaneous formation of MP and MPi is feasible. Here, we carried out thermogravimetry (TG) and differential scanning calorimetry (DSC) for sodium hypophosphite, and summar- ized the decomposition of sodium phosphate at different temperatures and flow rates of carrier gas, as shown in Figures S1 and S2 in Supporting Information. MP as an excellent hydrogen evolution electrocatalyst for water reduction has received much attention in photocatalytic hydrogen production. ${ }^{23-33}$ Many reports have claimed successful syntheses of MP-modified CdS for hydrogen evolution. Yet, none or only a trace amount of MP was detected in the XPS analyses. Furthermore, MPi as an excellent water oxidation catalyst has also been widely investigated for water electrolysis. ${ }^{34-39}$ However, the role of the dominant MPi product in the previous $\mathrm{MP} / \mathrm{CdS}$ systems was completely overlooked in photocatalytic hydrogen evolution. ${ }^{34}$

Herein, we demonstrate a dual-cocatalyst-modified CdS photocatalyst for hydrogen production, in which $\mathrm{NiCoP}$ and $\mathrm{NiCoPi}$ acted as reduction and oxidation cocatalysts, respectively. The fabrication of the photocatalyst is illustrated in Scheme 1. First, $\mathrm{NiCo}(\mathrm{OH})_{x}$ was deposited on $\mathrm{CdS}$ via a

Scheme 1. Schematic Illustration of the Formation of a NiCoP-NiCoPi Dual-Cocatalyst-Modified CdS Photocatalyst: (a) the $\mathrm{NiCo}(\mathrm{OH})_{x} / \mathrm{CdS}$ Precursor was Synthesized through a Hydrothermal Method (Step 1); and the Double-Heterojunction Photocatalyst was Prepared through a Vapor Deposition Method Using Sodium Hypophosphate as the Phosphorus Source (Step 2), (b) the Specific Process in Step 2

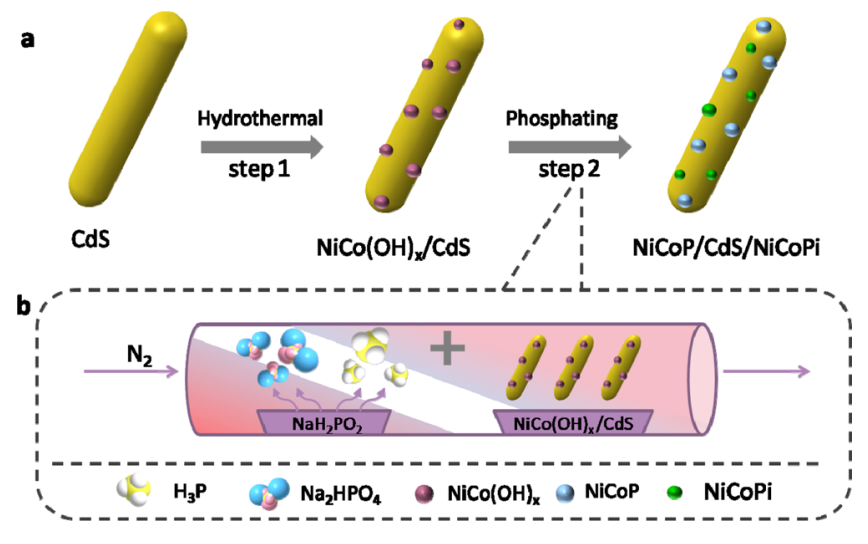

hydrothermal reaction. Then, the precursor was phosphated using sodium hypophosphate as the phosphorus source at 300 ${ }^{\circ} \mathrm{C}$ under an inert atmosphere. It was found that the flow rate of inert gas should be low enough $\left(\leq 10 \mathrm{~mL} \cdot \mathrm{min}^{-1}\right)$ to allow the metal hydroxide precursor to react with both phosphine and disodium hydrogen phosphate vapors, generating both $\mathrm{NiCoP}$ and $\mathrm{NiCoPi}$ cocatalysts on CdS. For a given cocatalyst loading concentration, the ratio between $\mathrm{NiCoP}$ and $\mathrm{NiCoPi}$ can be finely tuned by adjusting the [hypophosphate]/[metal precursor] ratio, which is discussed later.

The crystal structure of the as-prepared $\mathrm{NiCoP} / \mathrm{CdS} /$ $\mathrm{NiCoPi}$ photocatalysts with varied loading amounts of $\mathrm{NiCoP}-\mathrm{NiCoPi}$ cocatalysts from 1 to $9 \mathrm{~mol} \%$ was analyzed by XRD. As shown in Figure 1a, all the diffraction peaks of bare $\mathrm{CdS}$ are consistent with the hexagonal structure of $\mathrm{CdS}$ (JCPDS card no. 41-1049). ${ }^{47}$ However, after the modification with $\mathrm{NiCoP}-\mathrm{NiCoPi}$ cocatalysts, no obvious phase change in $\mathrm{CdS}$ is observed and no additional peaks from other phases appear. For $5 \% \mathrm{NiCoP} / \mathrm{NiCoPi} / \mathrm{CdS}$, inductive coupled plasma emission spectrometry (ICP-ES) (Table S2 in Supporting Information) confirmed that the actual loading 

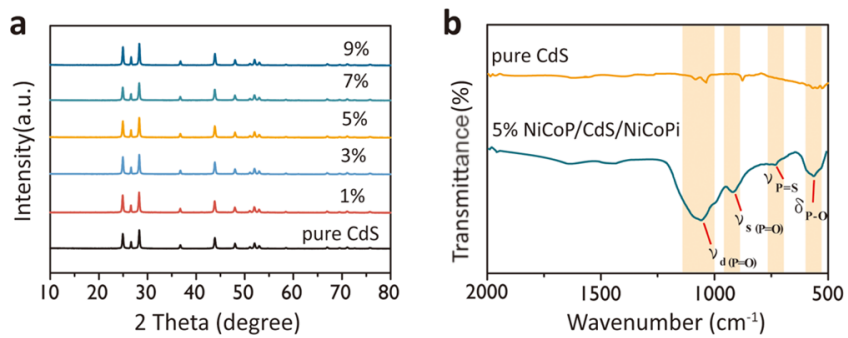

Figure 1. (a) Powder XRD patterns of as-synthesized CdS, and ( $x$ mol \%) NiCoP/CdS/NiCoPi samples $(x=1,3,5,7$, and 9), and (b) FTIR spectra of pure CdS and $5 \mathrm{~mol} \% \mathrm{NiCoP} / \mathrm{CdS} / \mathrm{NiCoPi}$ samples.

content of co-catalysts was $3.52 \mathrm{~mol} \%$, being about $30 \%$ lower than the theoretical value (Table S3 in Supporting Information). Even when the theoretical loading is as high as $9 \mathrm{~mol} \%$, no other phase is observed in XRD patterns, indicating that the loaded materials might either be amorphous, or be too few and too small, which is verified by TEM analysis.

Infrared spectroscopy confirmed the existence of phosphates in $\mathrm{NiCoP} / \mathrm{CdS} / \mathrm{NiCoPi}$. Figure $1 \mathrm{~b}$ shows the FTIR spectra of bare $\mathrm{CdS}$ and $5 \mathrm{~mol} \% \mathrm{NiCoP} / \mathrm{CdS} / \mathrm{NiCoPi}$ samples. Compared with the bare CdS sample, $5 \mathrm{~mol} \% \mathrm{NiCoP} / \mathrm{CdS} /$ $\mathrm{NiCoPi}$ photocatalyst shows extra FTIR absorption in the range of $500-1500 \mathrm{~cm}^{-1}$. Specifically, the peaks at 1050 and $907 \mathrm{~cm}^{-1}$ are assigned to the $\mathrm{P}=\mathrm{O}$ stretching vibration. The broad absorption in the range of $700-800 \mathrm{~cm}^{-1}$ is attributed to the $\mathrm{P}=\mathrm{S}$ stretching vibrations. The peak at $570 \mathrm{~cm}^{-1}$ is characteristic of the $\mathrm{P}-\mathrm{O}$ bending vibrations. All of these indicate the successful loading of phosphates on $\mathrm{CdS}$ in $\mathrm{NiCoP} / \mathrm{CdS} / \mathrm{NiCoPi}$.

The morphology and microstructure of the as-prepared bare $\mathrm{CdS}$ and $5 \mathrm{~mol} \% \mathrm{NiCoP} / \mathrm{CdS} / \mathrm{NiCoPi}$ photocatalysts were characterized by TEM. As shown in Figure 2a, the pristine CdS nanorods prepared in the first step (Scheme 1) have smooth surfaces with diameters of 30-100 nm. The HRTEM image of a CdS nanorod further shows its lattice structure and single crystalline nature (Figure $2 \mathrm{~b}$ ). It can be clearly seen that there are uniform lattice fringes with an interplanar spacing of 0.338 $\mathrm{nm}$, which can be attributed to the (002) plane of CdS. ${ }^{48}$ This result indicates that the nanorods grew along the direction of [001]. The fast Fourier transform (FFT) from the square (the inset in Figure $2 \mathrm{~b}$ ) reveals a structure of hexagonal CdS along the $[010]$ zone axis. Upon the loading of $\mathrm{NiCoP}-\mathrm{NiCoPi}$ cocatalysts, the nanorod morphology of CdS had no significant change, but the surface of nanorods became rough (Figure 2c). The FFT pattern obtained from the square area (the inset in Figure $2 \mathrm{~d}$ ) is indexed to the (001), (111), and (110) planes of hexagonal $\mathrm{NiCoP}$ along the $[\overline{1} 10]$ zone axis (JCPDS card no. 71-2336), revealing the existence of crystalline $\mathrm{NiCoP}$ nanoparticles. $^{49}$ Elemental mapping (Figure $2 \mathrm{f}-\mathrm{k}$ ) shows that $\mathrm{Ni}, \mathrm{Co}, \mathrm{P}$, and $\mathrm{O}$ are distributed over the whole surface of the CdS nanorod. The matching of the elemental distribution with the dark-field TEM image (the inset in Figure 2e) indicates a good dispersion of the dual-cocatalysts on CdS. In addition to TEM, we also studied the morphology and microstructure of $\mathrm{CdS}$ and $\mathrm{NiCoP} / \mathrm{CdS} / \mathrm{NiCoPi}$ with SEM. As shown in Figure S3, we did observe some surface roughness (as indicated with white circle marks) in $\mathrm{NiCoP} /$ $\mathrm{CdS} / \mathrm{NiCoPi}$, compared to CdS. However, no nanoparticles could be clearly observed on the surface of $\mathrm{CdS}$ upon the loading of NiCoP-NiCoPi cocatalysts. This may be because
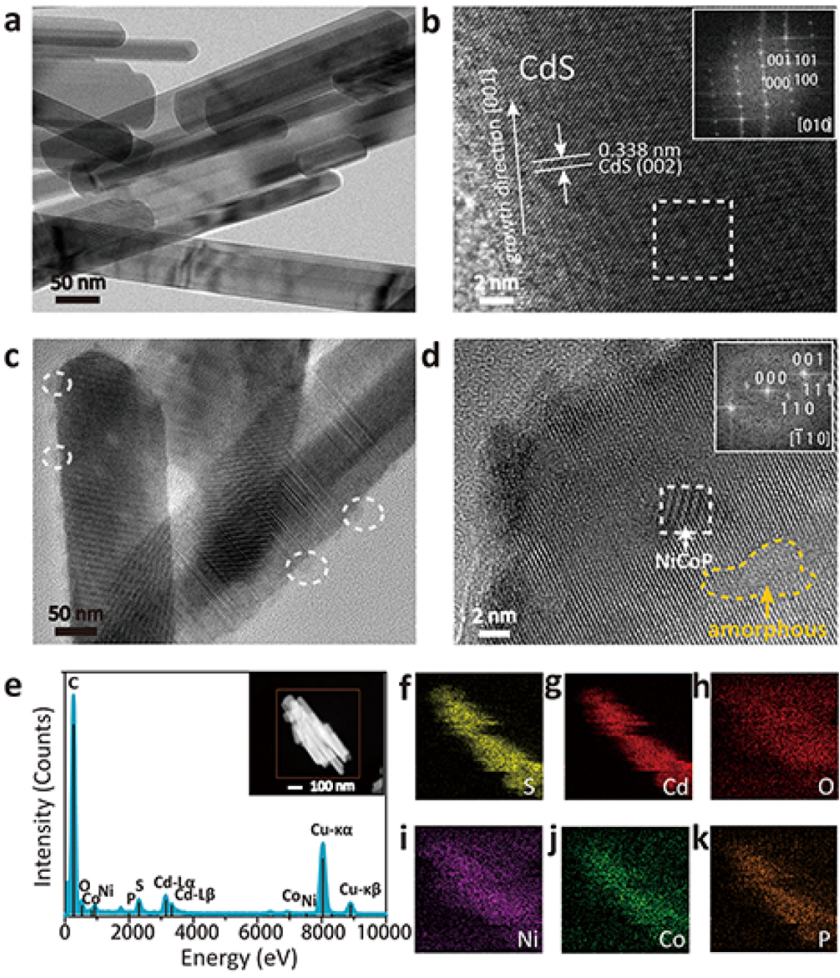

Figure 2. (a) TEM image of bare CdS, (b) HRTEM image of bare $\mathrm{CdS}$ (the inset is the FFT pattern obtained from the square area), (c) TEM image of $5 \mathrm{~mol} \% \mathrm{NiCoP} / \mathrm{CdS} / \mathrm{NiCoPi}$, (d) HRTEM image of $5 \mathrm{~mol} \% \mathrm{NiCoP} / \mathrm{CdS} / \mathrm{NiCoPi}$ (the inset is the FFT pattern obtained from the square area), (e) EDS spectrum of $5 \mathrm{~mol} \% \mathrm{NiCoP} / \mathrm{CdS} /$ $\mathrm{NiCoPi}$, and $(\mathrm{f}-\mathrm{k})$ elemental mapping of $\mathrm{S}, \mathrm{Cd}, \mathrm{O}, \mathrm{Ni}, \mathrm{Co}$, and $\mathrm{P}$ from the dark-field TEM image from the inset in (e).

the loading amount was too low, and/or loaded cocatalysts were too small to be observed with SEM.

The chemical composition and surface electronic states of the as-prepared bare $\mathrm{CdS}$ and $5 \mathrm{~mol} \% \mathrm{NiCoP} / \mathrm{CdS} / \mathrm{NiCoPi}$ photocatalysts were characterized using XPS. The corresponding XPS spectra calibrated using C 1s $(284.8 \mathrm{eV})$ as a reference are shown in Figure 3. Both pristine $\mathrm{CdS}$ and $\mathrm{NiCoP} / \mathrm{CdS} /$ $\mathrm{NiCoPi}$ samples show two $\mathrm{C} 1 \mathrm{~s}$ peaks of physically adsorbed carbon species (284.8 and $286.5 \mathrm{eV}$ ) (see Figure S4). The fine scan XPS spectra of CdS before and after NiCoP-NiCoPi loading are compared for $\mathrm{S} 2 \mathrm{p}, \mathrm{Cd} 3 \mathrm{~d}$, and $\mathrm{O} 1 \mathrm{~s}$ (Figure $3 \mathrm{a}-$ c). In the $S 2 p$ and Cd $3 d$ spectra (Figure $3 a, b$ ), the binding energies of both $\mathrm{S} 2 \mathrm{p}$ and $\mathrm{Cd} 3 \mathrm{~d}$ in $\mathrm{NiCoP} / \mathrm{CdS} / \mathrm{NiCoPi}$ are positively shifted, compared with those in CdS. The binding energies of S 2 p shift from 161.33 and 162.52 to 161.53 and $162.75 \mathrm{eV}$, respectively; while the binding energies of $\mathrm{Cd} 3 \mathrm{~d}$ shift from 404.98 and 411.74 to 405.07 and $411.87 \mathrm{eV}$, respectively. This result suggests that partial electrons were transferred from $\mathrm{CdS}$, contributing to the formation of $\mathrm{P}=\mathrm{S}$, which indicates the electronic interaction between $\mathrm{CdS}$ and cocatalysts. For the $\mathrm{O} 1 \mathrm{~s}$ spectra, the bare $\mathrm{CdS}$ only shows a weak XPS peak at $532.2 \mathrm{eV}$, which is assigned to physically adsorbed oxygen species (Figure 3c). However, after the loading of the cocatalysts, a new intense peak at $531.1 \mathrm{eV}$ is observed, which corresponds to the oxygen species in the phosphates. ${ }^{50,51}$ Lattice oxygen from nickel and cobalt oxides with a binding energy of about $529.0 \mathrm{eV}$ cannot be found, ${ }^{52-54}$ indicating the absence of nickel and cobalt oxides in the sample. 

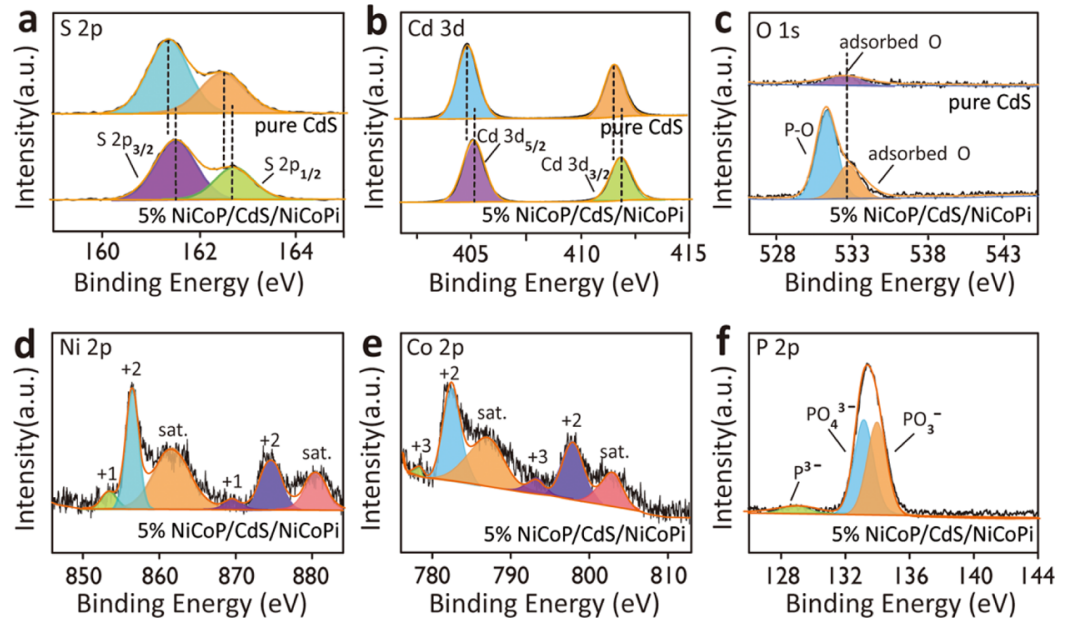

Figure 3. XPS fine scan spectra of (a) S 2p, (b) Cd 3d, (c) O 1s of as-synthesized bare CdS and 5 mol \% NiCoP/CdS/NiCoPi, (d) Ni 2p, (e) Co $2 \mathrm{p}$, and (f) P $2 \mathrm{p}$ of $5 \mathrm{~mol} \% \mathrm{NiCoP} / \mathrm{CdS} / \mathrm{NiCoPi}$.

For $5 \mathrm{~mol} \% \mathrm{NiCoP} / \mathrm{CdS} / \mathrm{NiCoPi}$, the $\mathrm{Ni} 2 \mathrm{p}$, Co $2 \mathrm{p}$, and $\mathrm{P}$ $2 p$ XPS spectra were also analyzed (Figure $3 d-f$ ). For the Ni $2 \mathrm{p}$ spectrum (Figure $3 \mathrm{~d}$ ), the intense peaks for $\mathrm{Ni} 2 \mathrm{p}_{3 / 2}$ are located at 853.4 and $856.5 \mathrm{eV}$, corresponding to $\mathrm{Ni}^{1+}$ and $\mathrm{Ni}^{2+}$ species, respectively. ${ }^{20}$ The $\mathrm{Ni} 2 \mathrm{p}_{1 / 2}$ region also shows two peaks at 869.6 and $874.8 \mathrm{eV}$ because of the coexistence of $\mathrm{Ni}^{1+}$ and $\mathrm{Ni}^{2+}$, respectively. The XPS peaks at higher binding energies of 862.3 and $881.3 \mathrm{eV}$ were assigned to the nickel satellite peaks. For the Co $2 \mathrm{p}$ spectrum (Figure $3 \mathrm{e}$ ), a pair of XPS peaks with binding energies of 781.9 and $797.8 \mathrm{eV}$ is attributed to $\mathrm{Co}^{2+}$; and the other pair at 777.9 and $793.0 \mathrm{eV}$ is attributed to $\mathrm{Co}^{3+} .55$ The cobalt satellite peaks are found at 787.15 and $802.73 \mathrm{eV}$. In the P 2p XPS spectrum (Figure 3f), three peaks located at 129.1, 133.1, and $134.0 \mathrm{eV}$ can be ascribed to $\mathrm{P}^{3-}, \mathrm{PO}_{4}{ }^{3-}\left(\mathrm{P}^{5+}\right)$, and $\mathrm{PO}^{3-}\left(\mathrm{P}^{5+}\right),{ }^{56,57}$ respectively, which confirms the simultaneous formation of phosphide and phosphate. Meanwhile, we also tested XPS for the used samples after three consecutive cycles (as shown in Figure S5). According to the atomic ratio from XPS before and after the reaction (Table S4), the relative content of $\mathrm{P}^{3-}$ is basically unchanged after the reaction, while the contents of $\mathrm{P}^{5+}, \mathrm{Ni}$, and Co become lower. This means that NiCoPi was partially photocorroded. The unchanged peak area for $\mathrm{NiCoP}$ indicates higher stability than that of $\mathrm{NiCoPi}$. The distribution of the dual cocatalysts on $\mathrm{CdS}$ before and after the cycling test is schematically illustrated in Figure S6b. For dual-cocatalystloaded photocatalysts, photocatalytic activity was determined by the minority (i.e., NiCoP). Because $\mathrm{NiCoPi}$ was excessive, the partial loss of $\mathrm{NiCoPi}$ had little effect on hydrogen production. This probably explains that photocatalytic hydrogen evolution by $\mathrm{NiCoP} / \mathrm{CdS} / \mathrm{NiCoPi}$ did not decay after three consecutive cycles.

The optical absorption of as-prepared bare CdS and $5 \mathrm{~mol} \%$ $\mathrm{NiCoP} / \mathrm{CdS} / \mathrm{NiCoPi}$ samples was evaluated using UV-visible diffuse-reflectance spectroscopy (UV-vis DRS). Figure 4a shows that both samples display a similar absorption edge around $500 \mathrm{~nm}$, which corresponds to a band gap of $2.43 \mathrm{eV}$ for pure $\mathrm{CdS}$. In addition, the $\mathrm{NiCoP} / \mathrm{CdS} / \mathrm{NiCoPi}$ photocatalyst shows stronger absorption in the visible light range than bare CdS. This is consistent with the color change of the sample from yellow to green (the inset in Figure 4a), which is another evidence for the successful loading of the NiCoP$\mathrm{NiCoPi}$ cocatalysts.
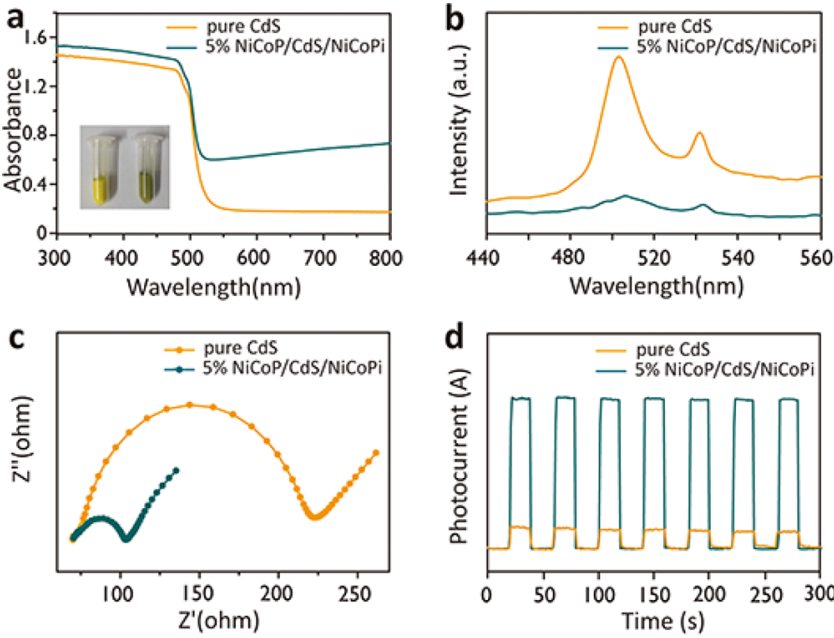

Figure 4. Optical and electrochemical analyses of bare $\mathrm{CdS}$ and $5 \mathrm{~mol}$ $\% \mathrm{NiCoP} / \mathrm{CdS} / \mathrm{NiCoPi}$ samples: (a) UV-vis absorption spectra, (b) PL spectra, (c) Nyquist plots from EIS, and (d) periodic on/off photocurrent response.

PL ES was used to investigate photogenerated electronhole recombination. Figure $4 \mathrm{~b}$ shows the PL spectra of bare $\mathrm{CdS}$ and $5 \mathrm{~mol} \% \mathrm{NiCoP} / \mathrm{CdS} / \mathrm{NiCoPi}$ samples, measured at an excitation wavelength of $420 \mathrm{~nm}$. Specifically, bare CdS nanorods show two strong emission peaks at 503 and $534 \mathrm{~nm}$, assigned to the intrinsic and extrinsic emissions, respectively. After loading $\mathrm{NiCoP}-\mathrm{NiCoPi}$ cocatalysts, there is no significant change in the positions of the emission peaks, while the intensity of these two peaks shows a dramatic decrease. The remarkable quenching of PL reveals that the cocatalysts had a striking effect on inhibiting the recombination of photogenerated electron-hole pairs. When photogenerated electron-hole pairs were generated in $\mathrm{CdS}, \mathrm{NiCoP}$ and $\mathrm{NiCoPi}$ on the $\mathrm{CdS}$ surface acted as electron and hole capturers, respectively, alleviating the recombination of photogenerated charge carriers in CdS.

Electrochemical measurements were performed to further investigate the interface electron transfer and charge separation in bare $\mathrm{CdS}$ and $5 \mathrm{~mol} \% \mathrm{NiCoP} / \mathrm{CdS} / \mathrm{NiCoPi}$ (Figure 4c). EIS was carried out to test the surface resistance of two samples. In general, the smaller the radius of the arc in the EIS 
Nyquist plot, the lower the electron transfer resistance of the tested material, meaning that the interface charge transfer is faster. Obviously, $5 \mathrm{~mol} \% \mathrm{NiCoP} / \mathrm{CdS} / \mathrm{NiCoPi}$ shows a smaller surface resistance (i.e., a smaller EIS arc radius) than that of bare $\mathrm{CdS}$, indicating that the loading of $\mathrm{NiCoP}-$ $\mathrm{NiCoPi}$ cocatalysts is beneficial for the separation and transfer of photogenerated electrons and holes. Meanwhile, a photocurrent test was performed in a three-electrode cell using bare $\mathrm{CdS}$ and $5 \mathrm{~mol} \% \mathrm{NiCoP} / \mathrm{CdS} / \mathrm{NiCoPi}$ as working electrodes under the irradiation of $420 \mathrm{~nm}$ light (Figure 4d). The photocurrent response of pristine $\mathrm{CdS}$ was very low, while that of $\mathrm{NiCoP} / \mathrm{CdS} / \mathrm{NiCoPi}$ was intensively enhanced, indicating that the modification of $\mathrm{NiCoP}$ and $\mathrm{NiCoPi}$ largely contributed to photogenerated carrier transportation and separation. What is more, EIS and photocurrent of $\mathrm{NiCoP}$ were also tested for comparison, as shown in Figure S7 in Supporting Information. The result shows that NiCoP had a higher electron transfer resistance and lower photocurrent, compared with $\mathrm{CdS}$ and $\mathrm{NiCoP} / \mathrm{CdS} / \mathrm{NiCoPi}$.

Photocatalytic hydrogen production by prepared samples was carried out under the irradiation of a $300 \mathrm{~W}$ xenon lamp equipped with a band cutoff filter $(420 \mathrm{~nm})$, using lactic acid as the sacrificial reagent. Lactic acid shows a higher hydrogen production efficiency than other sacrificial agents, such as TEOA and $\mathrm{Na}_{2} \mathrm{~S} / \mathrm{Na}_{2} \mathrm{SO}_{3}$ (see Figure S8). To confirm that the dual-cocatalysts, $\mathrm{NiCoP}$ and $\mathrm{NiCoPi}$, synergistically contributed to photocatalytic activity, single-cocatalyst $\mathrm{NiCoP}$ or $\mathrm{NiCoPi}$-modified CdS photocatalysts were prepared according to the method reported. ${ }^{37}$ Pure $\mathrm{CdS}$ and Pt loaded CdS samples were also used as reference for comparison. When a theoretical Pt loading content in $\mathrm{Pt} / \mathrm{CdS}$ was $10 \mathrm{~mol} \%$ (see Table S5 in Supporting Information), an actual loading content was measured to be $3.9 \mathrm{~mol} \%$. As shown in Figure $5 \mathrm{a}$, the hydrogen evolution rate of $\mathrm{NiCoP} / \mathrm{CdS} / \mathrm{NiCoPi}(80.8$
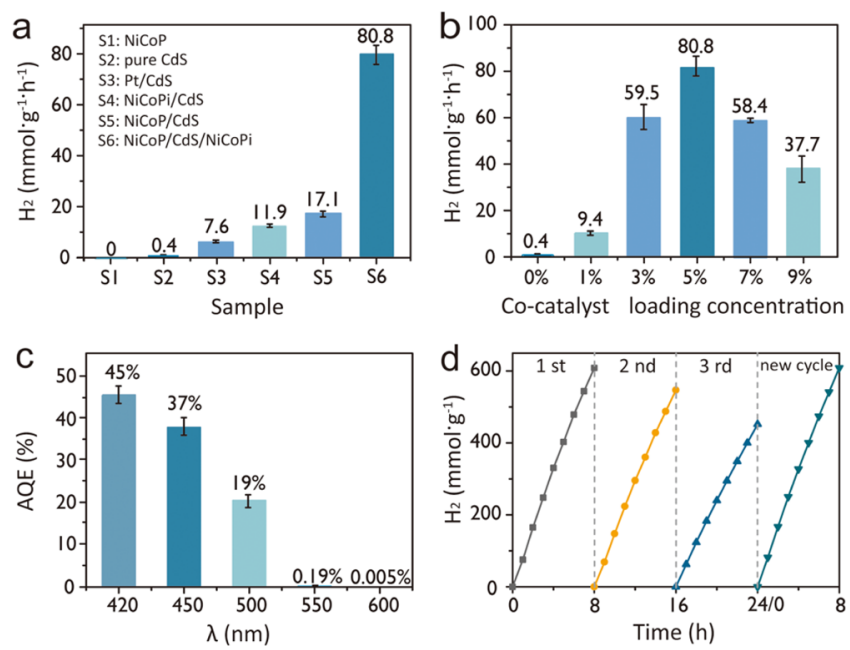

Figure 5. Photocatalytic performance: (a) hydrogen evolution rates of different samples $(\mathrm{S} 1=\mathrm{NiCoP}, \mathrm{S} 2=\mathrm{CdS}, \mathrm{S} 3=3.9 \% \mathrm{Pt} / \mathrm{CdS}, \mathrm{S} 4=$ $5 \% \mathrm{NiCoP} / \mathrm{CdS}, \mathrm{S} 5=5 \% \mathrm{NiCoP} / \mathrm{CdS}$, and $\mathrm{S} 6=5 \% \mathrm{NiCoPi} / \mathrm{CdS} /$ $\mathrm{NiCoPi})$, (b) cocatalyst content ( $x$ mol $\%, x=0,1,3,5,7$, and 9)dependent hydrogen evolution rates of the $\mathrm{NiCoP} / \mathrm{CdS} / \mathrm{NiCoPi}$ samples under visible light irradiation $(\lambda>420 \mathrm{~nm})$, (c) AQE of 5 $\mathrm{mol} \% \mathrm{NiCoP} / \mathrm{CdS} / \mathrm{NiCoPi}$ under different wavelengths of monochromatic light irradiation, and (d) cyclic photostability of the $5 \mathrm{~mol} \% \mathrm{NiCoP} / \mathrm{CdS} / \mathrm{NiCoPi}$ photocatalyst with prolonged visible light irradiation $(\lambda>420 \mathrm{~nm})$ for $32 \mathrm{~h}$. $\left.\mathrm{mmol} \cdot \mathrm{g}^{-1} \cdot \mathrm{h}^{-1}\right)$ is about $202,11,4.7$, and 7 times higher than that of CdS $\left(0.4 \mathrm{mmol} \cdot \mathrm{g}^{-1} \cdot \mathrm{h}^{-1}\right), \mathrm{Pt} / \mathrm{CdS}\left(7.6 \mathrm{mmol} \cdot \mathrm{g}^{-1} \cdot \mathrm{h}^{-1}\right), 5$ $\mathrm{mol} \% \mathrm{NiCoP} / \mathrm{CdS}\left(17.1 \mathrm{mmol} \cdot \mathrm{g}^{-1} \cdot \mathrm{h}^{-1}\right)$, and $5 \mathrm{~mol} \%$ $\mathrm{NiCoPi} / \mathrm{CdS}\left(11.9 \mathrm{mmol} \cdot \mathrm{g}^{-1} \cdot \mathrm{h}^{-1}\right)$, respectively, indicating that the dual-cocatalysts played a more important role in photocatalytic hydrogen production than the single ones. Although various MP-decorated $\mathrm{CdS}$ photocatalysts have been investigated, to the best of our knowledge, the enhancement factor reported here (using pristine $\mathrm{CdS}$ as a reference) is extremely high (see Table S1 in Supporting Information).$^{26}$ Interestingly, the HER rate of the $\mathrm{NiCoPi} / \mathrm{CdS} / \mathrm{NiCoP}$ composite was much higher than the sum of those of $\mathrm{NiCoP} / \mathrm{CdS}$ and $\mathrm{NiCoPi} / \mathrm{CdS}$. As we all know, only when photogenerated electrons and holes can be consumed equally and efficiently, considerable photocatalytic activity can be achieved. Therefore, a good photocatalytic system needs both oxidation and reduction cocatalysts. If there exists only a reduction cocatalyst that facilitates the consumption of photogenerated electrons, photogenerated holes are accumulated in CdS. These holes can easily combine with the electrons photogenerated later in $\mathrm{CdS}$, or vice versa. Therefore, the coexistence of oxidation and reduction cocatalysts can have a synergetic effect in photocatalysis.

To explore the synergy between $\mathrm{NiCoP}$ and $\mathrm{NiCoPi}$, the effect of $\mathrm{NiCoP} / \mathrm{NiCoPi}$ ratio on photocatalytic activity was investigated for a fixed theoretical loading content of cocatalysts (i.e., $5 \mathrm{~mol} \% \mathrm{NiCoP} / \mathrm{NiCoPi}$ ). According to eq 2 , more phosphine is generated from the phosphating reaction shown in Scheme 1, if more sodium hypophosphate is fed. By simply adjusting the [hypophosphate]/[metal precursor] ratio, the $\mathrm{NiCoP} / \mathrm{NiCoPi}$ ratio was finely tuned. The ratio of $\mathrm{NiCoP}$ to $\mathrm{NiCoPi}\left(\mathrm{P}^{3-} / \mathrm{P}^{5+}\right)$ in the different samples measured by XPS increased gradually with the dose of sodium hypophosphate (see Figure S9a-d in Supporting Information). Photocatalytic hydrogen evolution was tested for $\mathrm{NiCoP} / \mathrm{CdS} / \mathrm{NiCoPi}$ prepared with varied [hypophosphate]/[metal precursor] molar ratios from 10 to 40 . Photocatalytic activity increased first and then decreased with the increasing phosphide/ phosphate ratio $\left(\mathrm{P}^{3-} / \mathrm{P}^{5+}\right)$ (Figure $\mathrm{S} 9 \mathrm{e}$ ). The reason can be explained as follows. When a cocatalyst ( $\mathrm{NiCoP}-\mathrm{NiCoPi})$ loading amount was too small, the hydrogen evolution activity increased with the cocatalysts loaded because of an increase of catalytic active spots, as illustrated in the first three panels of Figure S9f. However, photocatalytic activity decreased when the ratio of $\mathrm{P}^{3-} / \mathrm{P}^{5+}$ was increased to 30 . This is because the excessive coverage of the cocatalysts could cause the direct contact between the reduction cocatalyst $(\mathrm{NiCoP})$ and the oxidation cocatalyst $(\mathrm{NiCoPi})$, forming recombination centers (as illustrated in the last panel of Figure S9f). In addition, the overloading of cocatalysts also blocked incident light, hindering the excitation and generation of photogenerated charge carriers.

Figure $5 \mathrm{~b}$ shows the effect of the amount of dual-cocatalysts on photocatalytic activity. The optimal loading amount of the cocatalysts was $5 \mathrm{~mol} \%$, showing an average hydrogen evolution rate of $80.8 \mathrm{mmol} \cdot \mathrm{g}^{-1} \cdot \mathrm{h}^{-1}$. We also investigated the effect of the $\mathrm{Ni}-\mathrm{Co}$ ratio on the hydrogen generation (Figure $\mathrm{S} 10$ in Supporting Information). When the $\mathrm{Ni}-\mathrm{Co}$ ratio was changed from $1: 2$ to $2: 1$, the hydrogen production activity increased first and then dropped. The optimal $\mathrm{Ni}-\mathrm{Co}$ ratio was around $1: 1$.

Photocatalytic hydrogen evolution by $5 \mathrm{~mol} \% \mathrm{NiCoP} / \mathrm{CdS} /$ $\mathrm{NiCoPi}$ photocatalyst was tested under different wavelengths 
of monochromatic light. The irradiation wavelength-dependent AQE was calculated according to eq 1 . The AQE of Pt-loaded $\mathrm{CdS}$ was also tested for comparison, and the quantum efficiency of $3.95 \%$ (actual loading content) $\mathrm{Pt} / \mathrm{CdS}$ was $1.93 \%$ at $420 \mathrm{~nm}$. The AQE of $\mathrm{NiCoP} / \mathrm{CdS} / \mathrm{NiCoPi}$ at 420 , 450 , and $500 \mathrm{~nm}$ was 45, 37, and 19\%, respectively (Figure $5 c)$. When the energy of incident light was smaller than the bandgap of $\mathrm{CdS}$, the $\mathrm{AQE}$ became negligible, indicating that the absorption by the dual-cocatalysts in the range of 500-800 $\mathrm{nm}$ (Figure $4 \mathrm{a}$ ) had little contribution to the hydrogen evolution.

It is well known that the durability of photocatalysts is essential for their practical application. Therefore, the cyclic stability of the photocatalyst was studied (Figure $5 \mathrm{~d}$ ). $5 \mathrm{~mol} \%$ $\mathrm{NiCoP} / \mathrm{CdS} / \mathrm{NiCoPi}$ photocatalyst was subjected to three consecutive cycles of photocatalytic measurement, with each cycle lasting for $8 \mathrm{~h}$. The experimental results showed that the catalyst still exhibited considerable hydrogen production activity during $24 \mathrm{~h}$ of testing. The decrease in activity during the second and third cycles is suspected to originate from the consumption of the sacrificial agent. A similar phenomenon was also observed for the bare CdS photocatalyst (Figure S11 in Supporting Information). To confirm this assumption, the photocatalyst was collected after the third cycle and a fresh sacrificial agent solution with the same concentration was used for a new cycle measurement. It was found that the hydrogen production recovered to the same level as the first cycle. However, for bare CdS, approximately $13 \%$ of photocatalytic hydrogen evolution activity could not be recovered because of the photocorrosion of CdS. ${ }^{58,59}$ All the above tests showed that $\mathrm{NiCoP} / \mathrm{CdS} / \mathrm{NiCoPi}$ exhibited both superior activity and stability to bare CdS.

To test the universality of the dual-cocatalyst system ( $\mathrm{NiCoP}-\mathrm{NiCoPi}$, we performed the hydrogen production by the $(\mathrm{NiCoP}-\mathrm{NiCoPi})$ cocatalysts on another substrate, g$\mathrm{C}_{3} \mathrm{~N}_{4}$. As shown in Figure $\mathrm{S} 12$, by loading $5 \%$ cocatalysts ( $\mathrm{NiCoP}-\mathrm{NiCoPi}$ ) on $\mathrm{g}^{-} \mathrm{C}_{3} \mathrm{~N}_{4}$, the hydrogen production by $\mathrm{NiCoP} / \mathrm{g}-\mathrm{C}_{3} \mathrm{~N}_{4} / \mathrm{NiCoPi}$ was also greatly improved (from 0 to $\left.175 \mu \mathrm{mol} \cdot \mathrm{g}^{-1} \cdot \mathrm{h}^{-1}\right)$.

It is generally accepted that freshly synthesized MPs experience a surface passivation after being stored in air, forming a thin layer of metal phosphates. ${ }^{60}$ Such a passivation layer can protect the MPs from further oxidation, and it can also be reversibly converted to their original state through reduction (so called surface activation) (Figure 6a). The hydrogen evolution mechanisms of the single- and dualcocatalyst-modified CdS photocatalysts are proposed in Figure $6 \mathrm{~b}, \mathrm{c}$, respectively. For the single-cocatalyst-modified CdS, the surface passivation layer is reduced by photogenerated electrons at the beginning of the photocatalytic process (step 1, Figure $6 \mathrm{~b}$ ). The activated $\mathrm{NiCoP}$ nanoparticles act as electron acceptors and hydrogen evolution sites. During the photocatalytic process, electrons that flow continuously from $\mathrm{CdS}$ to NiCoP nanoparticles will be eventually captured by protons adsorbed on the surfaces of the cocatalyst, generating hydrogen (Figure 6b), while the photogenerated holes left on the CdS surface will oxidize lactic acid (the sacrificial agent). This explains the performance enhancement of $\mathrm{NiCoP} / \mathrm{CdS}$, compared with bare CdS. Therefore, photocatalytic activity of the single-cocatalyst-modified CdS system is normally limited by sacrificial agent oxidation, which can be enhanced by the deposition of an oxidation cocatalyst (e.g., NiCoPi). The simultaneous loading of $\mathrm{NiCoP}$ and $\mathrm{NiCoPi}$ on the $\mathrm{CdS}$ forms

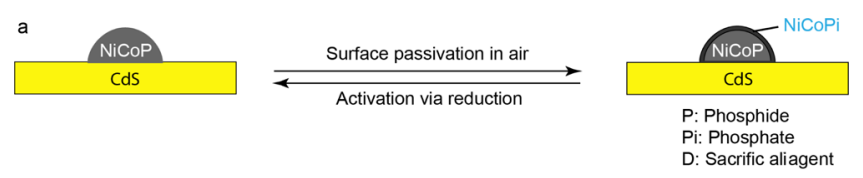

b

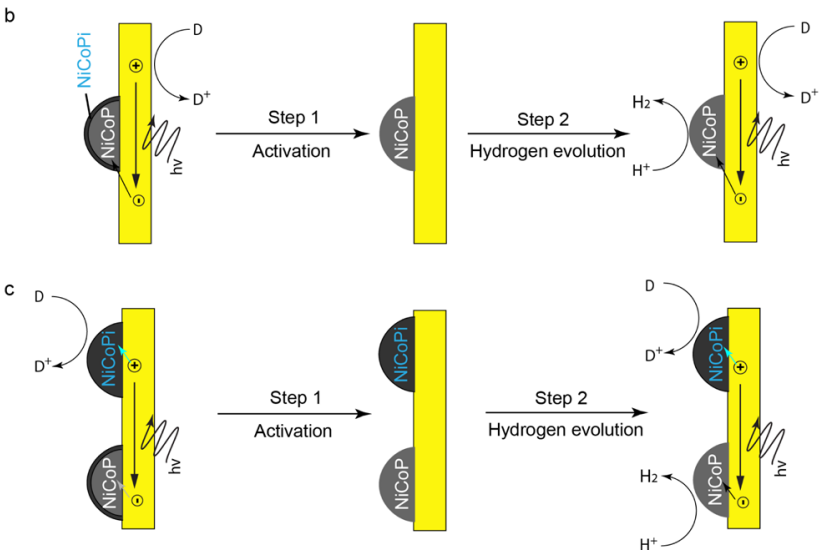

Figure 6. Diagram illustrating (a) surface passivation and activation of metal-phosphide, and photocatalytic hydrogen evolution by (b) single- and (c) dual-cocatalyst-modified CdS photocatalysts.

a dual-cocatalyst-modified photocatalyst (Figure 6c), further promoting the photogenerated carrier separation. NiCoP nanoparticles act as the electron acceptor and hydrogen evolution cocatalyst, while NiCoPi electron donor and the cocatalyst for sacrificial agent oxidation. Only when the proton reduction rate matches the oxidation rate of the sacrificial agent, the hydrogen evolution will be maximized. This can be achieved by tuning the ratio between the reduction cocatalyst and the oxidation cocatalyst (see Figure S9).

In the field of electrocatalysis, MPs and metal phosphates are efficient hydrogen evolution electrocatalysts and oxygen evolution electrocatalysts, respectively. ${ }^{23-39}$ Using MPs for photocatalytic hydrogen evolution has been well established. ${ }^{23-33}$ Whether metal phosphates can act as oxygen evolution catalysts in photocatalytic systems is not clear. To answer this, overall photocatalytic water splitting was performed by using $\mathrm{NiCoP} / \mathrm{CdS}$ and $\mathrm{NiCoP} / \mathrm{CdS} / \mathrm{NiCoPi}$ photocatalysts. It was found that $\mathrm{NiCoP} / \mathrm{CdS}$ did not show any hydrogen evolution activity. This is because the reduction half reaction would be restrained without the participation of the oxidation half reaction. However, for the dual-cocatalyst system, a hydrogen evolution rate of $233 \mu \mathrm{mol} \cdot \mathrm{g}^{-1} \cdot \mathrm{h}^{-1}$ was observed, indicating that $\mathrm{NiCoPi}$ as an oxidation cocatalyst was important in water splitting (see Figure S13 in Supporting Information).

To better explain the above experimental results and propose the photocatalytic mechanism of $\mathrm{NiCoP} / \mathrm{CdS} /$ $\mathrm{NiCoPi}$, the electronic band structure of $\mathrm{NiCoP}, \mathrm{NiCoPi}$, and CdS was studied. As shown in Figure S14 in Supporting Information, the bandgap energy $(2.42 \mathrm{eV})$ of $\mathrm{NiCoP} / \mathrm{CdS} /$ $\mathrm{NiCoPi}$ and $\mathrm{CdS}$ was obtained by UV-vis absorption spectroscopy. As shown in Figure S15 in Supporting Information, the conduction band $(\mathrm{CB})$ of $\mathrm{CdS}$, obtained from Mott-Schottky plots, was $-0.72 \mathrm{~V}$ versus $\mathrm{Ag} / \mathrm{AgCl}$ $\left(-0.52 \mathrm{~V}\right.$ vs NHE). According to $E_{\mathrm{VB}}=E_{\mathrm{CB}}+E_{\mathrm{g}}$, the $\mathrm{VB}$ of $\mathrm{CdS}$ was $-6.4 \mathrm{eV}$ (vs vacuum level). Theoretical computation using density functional theory was conducted to derive the band structure and work function of $\mathrm{NiCoP}$, from which $\mathrm{NiCoP}$ had metallic characteristic with nonzero density of 


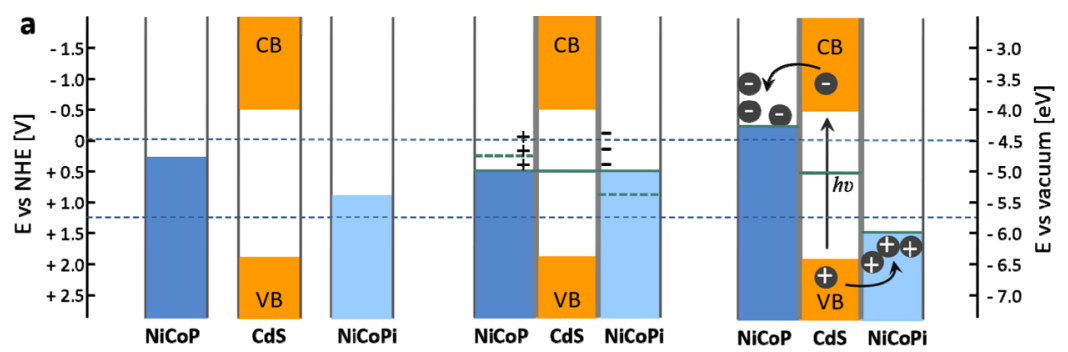

(1)

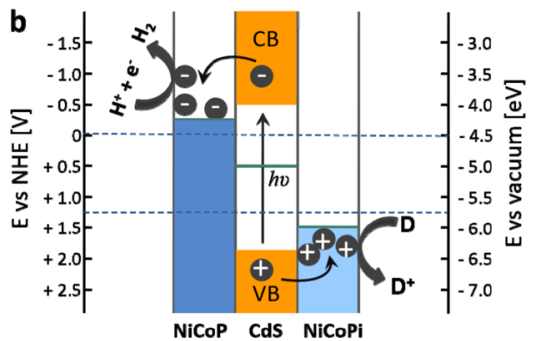

(2)

C

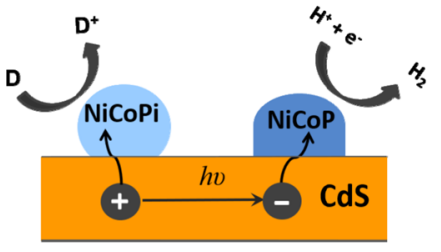

Figure 7. Diagram illustrating the charge separation and transfer at the interfaces of $\mathrm{NiCoP} / \mathrm{CdS} / \mathrm{NiCoPi}$ : (a) band structures of $\mathrm{NiCoPi}, \mathrm{CdS}$, and $\mathrm{NiCoPi}(1), \mathrm{NiCoP} / \mathrm{CdS} / \mathrm{NiCoPi}$ heterojunctions under thermal equilibrium (2), and at the beginning of the photocatalytic process (3); (b) and (c) schemes of photocatalytic hydrogen production.

states (DOS) crossing the Fermi energy level (see Figure S16 in Supporting Information). Then, the work function was calculated to reveal the charge injection at the $\mathrm{NiCoP} / \mathrm{CdS}$ interface. In our model system, the work function of the metallic NiCoP (111) and CdS (002) surface was 4.86 and $5.00 \mathrm{eV}$, respectively. Therefore, photogenerated electrons in the $\mathrm{CB}$ of $\mathrm{CdS}$ can be transferred to $\mathrm{NiCoP}$, which acted as the active sites for proton reduction. Meanwhile, the Kelvin probe system was applied to detect the work function of $\mathrm{NiCoPi}$ $(5.44 \mathrm{eV})$, less positive than the valence band (VB) of CdS ( $-6.4 \mathrm{eV}$ vs vacuum level). Thus, the holes in the VB of CdS can be trapped by $\mathrm{NiCoPi}$.

Figure 7 shows the plausible charge separation at the interfaces of $\mathrm{NiCoP} / \mathrm{CdS} / \mathrm{NiCoPi}$. Before contact, $\mathrm{CdS}(\emptyset=5$ $\mathrm{eV}), \mathrm{NiCoP}(\emptyset=4.86 \mathrm{eV})$, and $\mathrm{NiCoPi}(\emptyset=5.44 \mathrm{eV})$ are independent of each other, without any interaction (Figure 7a1). When they contact with each other (i.e., the formation of double-heterojunction $\mathrm{NiCoP} / \mathrm{CdS} / \mathrm{NiCoPi}$ ), the built-in electric field would form at the interfaces (Figure 7a-2). The built-in electric field drives the electrons to migrate through heterojunctions, eventually reaching thermal equilibrium and forming a new Fermi energy level at $-5 \mathrm{eV}$ (vs the vacuum energy level) (Figure 7a-2). Under sunlight irradiation, CdS nanorods generate photogenerated electron-hole pairs. Then, because of the lower reduction potential of $\mathrm{NiCoP}$, electrons are transferred from $\mathrm{CdS}$ to $\mathrm{NiCoP}$. At the same time, the holes preferably migrate from $\mathrm{CdS}$ to $\mathrm{NiCoPi}$ because of the lower oxidation potential of $\mathrm{NiCoPi}$ (Figure 7a-3). Thereafter, the reduction of protons and the oxidation of a sacrificial agent take place on the surface of the cocatalysts, and continuous and stable hydrogen evolution is realized, as illustrated in Figure $7 \mathrm{~b}, \mathrm{c}$.

\section{CONCLUSIONS}

In summary, we developed a novel and efficient $\mathrm{NiCoP} / \mathrm{CdS} /$ $\mathrm{NiCoPi}$ photocatalyst that incorporated both reduction and oxidation cocatalysts for photocatalytic hydrogen generation. The NiCoP-NiCoPi dual-cocatalysts were simultaneously deposited on $\mathrm{CdS}$ via a simple phosphating step using volatile decomposition products from sodium hypophosphate as the phosphorus source. The two distinct cocatalysts in contact with $\mathrm{CdS}$ facilitated electron and hole transfer to the corresponding acceptors. The photocurrent of $\mathrm{NiCoP} / \mathrm{CdS} /$ $\mathrm{NiCoPi}$ enlarged significantly, compared with bare $\mathrm{CdS}$, while its electrical impedance and PL emission decreased dramatically. The dual cocatalysts acted as reduction and oxidation sites for hydrogen evolution and sacrificial reagent oxidation, respectively. Upon the loading of dual cocatalysts, the visiblelight-driven hydrogen evolution by $\mathrm{CdS}$ was greatly enhanced. The modified CdS with a cocatalyst loading content of $5 \mathrm{~mol}$ $\%$ showed a hydrogen evolution rate of $80.8 \mathrm{mmol} \cdot \mathrm{g}^{-1} \cdot \mathrm{h}^{-1}$, which was 202 times higher than that of bare CdS $(0.4 \mathrm{mmol}$. $\left.\mathrm{g}^{-1} \cdot \mathrm{h}^{-1}\right)$. It also exhibited remarkable durability for a continuous photocatalytic test with a total reaction time of $24 \mathrm{~h}$. Finally, the work described here integrating a visible-light absorbing semiconductor with noble-metal-free reduction and oxidation cocatalysts opens up a viable strategy to the design of simple, robust, and cost-effective photocatalysts for solar fuel production.

\section{ASSOCIATED CONTENT}

\section{Supporting Information}

The Supporting Information is available free of charge at https://pubs.acs.org/doi/10.1021/acsami.0c12790.

Comparison of some CdS-based photocatalytic systems using MPs as the cocatalysts for photocatalytic $\mathrm{H}_{2}$ production in the literature; TG and DSC curves of sodium hypophosphite; thermal decomposition of sodium phosphate at different temperatures and flow rates of the carrier gas; ICP results of $5 \mathrm{~mol} \% \mathrm{NiCoP} /$ $\mathrm{NiCoPi} / \mathrm{CdS}$; theoretical and actual loading contents of $\mathrm{NiCoP}-\mathrm{NiCoPi}, \mathrm{NiCoP}$, and $\mathrm{NiCoPi}$ in the $5 \% \mathrm{NiCoP} /$ $\mathrm{NiCoPi} / \mathrm{CdS}$ composite; XPS survey scan spectra of pure $\mathrm{CdS}$ and $5 \mathrm{~mol} \% \mathrm{NiCoP} / \mathrm{NiCoPi} / \mathrm{CdS}$ samples; XPS fine scan spectra of $\mathrm{C} 1 \mathrm{~s}$ of pure $\mathrm{CdS}$ and $5 \mathrm{~mol} \%$ $\mathrm{NiCoP} / \mathrm{NiCoPi} / \mathrm{CdS}$ samples; XPS fine scan spectra of $\mathrm{S} 2 \mathrm{p}, \mathrm{Cd} 3 \mathrm{~d}, \mathrm{O} 1 \mathrm{~s}, \mathrm{Ni} 2 \mathrm{p}, \mathrm{Co} 2 \mathrm{p}$, and P $2 \mathrm{p}$ of $5 \mathrm{~mol} \%$ $\mathrm{NiCoP} / \mathrm{NiCoPi} / \mathrm{CdS}$ after the photocatalytic reaction; 
elemental ratios in $5 \mathrm{~mol} \% \mathrm{NiCoP} / \mathrm{NiCoPi} / \mathrm{CdS}$ before and after the reaction (from XPS); Nyquist plots from EIS and periodic on/off photocurrent response of $\mathrm{NiCoP}, \mathrm{CdS}$, and $\mathrm{NiCoP} / \mathrm{NiCoPi} / \mathrm{CdS}$ samples; XPS fine scan spectra of $\mathrm{P} 2 \mathrm{p}$ in $5 \mathrm{~mol} \% \mathrm{NiCoP} / \mathrm{CdS} /$ NiCoPi prepared by different [hypophosphate]/[metal precursor] ratios; $\mathrm{P}^{3-} / \mathrm{P}^{5+} \mathrm{XPS}$ area ratio and hydrogen production activity of $5 \mathrm{~mol} \% \mathrm{NiCoP} / \mathrm{CdS} / \mathrm{NiCoPi}$ prepared by different [hypophosphate]/[metal precursor] ratios; hydrogen evolution by $\mathrm{NiCoP} / \mathrm{CdS} / \mathrm{NiCoPi}$ samples with different $\mathrm{Ni}-\mathrm{Co}$ ratios under visible light irradiation $(\lambda>420 \mathrm{~nm})$; cyclic photostability of the $\mathrm{CdS}$ photocatalyst with prolonged visible light irradiation $(\lambda>420 \mathrm{~nm})$ for $32 \mathrm{~h}$; gas $\left(\mathrm{H}_{2}\right.$ and $\left.\mathrm{O}_{2}\right)$ evolution by $\mathrm{NiCoP} / \mathrm{CdS} / \mathrm{NiCoPi}$ for overall water splitting in the absence of a sacrificing agent; bandgap of pure CdS and $5 \mathrm{~mol} \% \mathrm{NiCoP} / \mathrm{NiCoPi} / \mathrm{CdS}$ samples; Mott-Schottky plots of $\mathrm{CdS}$; and band structures and DOS of NiCoP (PDF)

\section{AUTHOR INFORMATION}

\section{Corresponding Authors}

Jiefang Zhu - Department of Chemistry-Ångstrom Laboratory, Uppsala University, SE-75121 Uppsala, Sweden; 자이.org/ 0000-0002-6326-8106; Email: jiefang.zhu@kemi.uu.se

Yuanhui Zheng - College of Chemistry, Fuzhou University, Fuzhou, Fujian 350116, China; 이이이.org/0000-00016326-727X; Email: yuanhui.zheng@fzu.edu.cn

\section{Authors}

Yi Zhao - College of Chemistry, Fuzhou University, Fuzhou, Fujian 350116, China

Yongfeng Lu - College of Chemistry, Fuzhou University, Fuzhou, Fujian 350116, China

Lu Chen - College of Chemistry, Fuzhou University, Fuzhou, Fujian 350116, China

Xiaofeng Wei - National Engineering Research Center of Chemical Fertilizer Catalyst, Fuzhou University, Fuzhou, Fujian 350002, China

Complete contact information is available at:

https://pubs.acs.org/10.1021/acsami.0c12790

\section{Notes}

The authors declare no competing financial interest.

\section{ACKNOWLEDGMENTS}

This work was funded by the National Nature Science Foundation of China (grant no. 61605028 and 61775040), Program for Minjiang Scholar (Y.Z.), Program for Thousand Young Talent plan (Y.Z.), Stiftelsen Olle Engkvist Byggmästare (grant no. SOEB-2015/167), the Swedish Research Council (2018-06868), and the Swedish Energy Agency (46641-1).

\section{REFERENCES}

(1) Christoforidis, K. C.; Fornasiero, P. Photocatalytic Hydrogen Production: A Rift into the Future Energy Supply. ChemCatChem 2017, 9, 1523-1544.

(2) Maeda, K.; Domen, K. Photocatalytic Water Splitting: Recent Progress and Future Challenges. J. Phys. Chem. Lett. 2010, 1, 26552661.

(3) Züttel, A. Hydrogen Storage Methods. Naturwissenschaften 2004, 91, 157-172.
(4) Liu, X.; Iocozzia, J.; Wang, Y.; Cui, X.; Chen, Y.; Zhao, S.; Li, Z.; Lin, Z. Noble Metal-Metal Oxide Nanohybrids with Tailored Nanostructures for Efficient Solar Energy Conversion, Photocatalysis and Environmental Remediation. Energy Environ. Sci. 2017, 10, 402434.

(5) Hisatomi, T.; Kubota, J.; Domen, K. Recent Advances in Semiconductors for Photocatalytic and Photoelectrochemical Water Splitting. Chem. Soc. Rev. 2014, 43, 7520-7535.

(6) Chen, X.; Shen, S.; Guo, L.; Mao, S. S. Semiconductor-based Photocatalytic Hydrogen Generation. Chem. Rev. 2010, 110, 65036570.

(7) Cheng, L.; Xiang, Q.; Liao, Y.; Zhang, H. CdS-Based Photocatalysts. Energy Environ. Sci. 2018, 11, 1362-1391.

(8) Xu, Y.; Huang, Y.; Zhang, B. Rational Design of Semiconductorbased Photocatalysts for Advanced Photocatalytic Hydrogen Production: The Case of Cadmium Chalcogenides. Inorg. Chem. Front. 2016, 3, 591-615.

(9) Wang, Q.; Nakabayashi, M.; Hisatomi, T.; Sun, S.; Akiyama, S.; Wang, Z.; Pan, Z.; Xiao, X.; Watanabe, T.; Yamada, T.; Shibata, N.; Takata, T.; Domen, K. Oxysulfide Photocatalyst for Visible-lightdriven Overall Water Splitting. Nat. Mater. 2019, 18, 827-832.

(10) Li, W.; Xie, S.; Li, M.; Ouyang, X.; Cui, G.; Lu, X.; Tong, Y. $\mathrm{CdS} / \mathrm{CeO}_{\mathrm{x}}$ Heterostructured Nanowires for Photocatalytic Hydrogen Production. J. Mater. Chem. A 2013, 1, 4190-4193.

(11) Yu, H.; Liu, R.; Wang, X.; Wang, P.; Yu, J. Enhanced Visiblelight Photocatalytic Activity of $\mathrm{Bi}_{2} \mathrm{WO}_{6}$ Nanoparticles by $\mathrm{Ag}_{2} \mathrm{O}$ Cocatalyst. Appl. Catal., B 2012, 111-112, 326-333.

(12) Yuan, J.; Wen, J.; Gao, Q.; Chen, S.; Li, J.; Li, X.; Fang, Y. Amorphous $\mathrm{Co}_{3} \mathrm{O}_{4}$ Modified CdS Nanorods with Enhanced Visiblelight Photocatalytic $\mathrm{H}_{2}$-production Activity. Dalton Trans. 2015, 44, $1680-1689$.

(13) Hou, Y.; Zhu, Y.; Xu, Y.; Wang, X. Photocatalytic Hydrogen Production Over Carbon Nitride Loaded with $\mathrm{WS}_{2}$ as Cocatalyst under Visible Light. Appl. Catal., B 2014, 156-157, 122-127.

(14) Gopannagari, M.; Kumar, D. P.; Reddy, D. A.; Hong, S.; Song, M. I.; Kim, T. K. In Situ Preparation of Few-layered WS 2 Nanosheets and Exfoliation into Bilayers on CdS Nanorods for Ultrafast Charge Carrier Migrations toward Enhanced Photocatalytic Hydrogen Production. J. Catal. 2017, 351, 153-160.

(15) Reddy, D. A.; Park, H.; Ma, R.; Kumar, D. P.; Lim, M.; Kim, T. K. Heterostructured $\mathrm{WS}_{2}-\mathrm{MoS}_{2}$ Ultrathin Nanosheets Integrated on CdS Nanorods to Promote Charge Separation and Migration and Improve Solar-Driven Photocatalytic Hydrogen Evolution. ChemSusChem 2017, 10, 1563-1570.

(16) Li, C.; Wang, H.; Naghadeh, S. B.; Zhang, J. Z.; Fang, P. Visible Light Driven Hydrogen Evolution by Photocatalytic Reforming of Lignin and Lactic Acid Using One-dimensional NiS/CdS Nanostructures. Appl. Catal., B 2018, 227, 229-239.

(17) Ma, B.; Xu, H.; Lin, K.; Li, J.; Zhan, H.; Liu, W.; Li, C. $\mathrm{Mo}_{2} \mathrm{C}$ as Non-Noble Metal Co-Catalyst in $\mathrm{Mo}_{2} \mathrm{C} / \mathrm{CdS}$ Composite for Enhanced Photocatalytic $\mathrm{H}_{2}$ Evolution under Visible Light Irradiation. ChemSusChem 2016, 9, 820-824.

(18) Gao, F.; Zhao, Y.; Zhang, L.; Wang, B.; Wang, Y.; Huang, X.; Wang, K.; Feng, W.; Liu, P. Well Dispersed MoC Quantum Dots in Ultrathin Carbon Films as Efficient Co-catalysts for Photocatalytic $\mathrm{H}_{2}$ Evolution. J. Mater. Chem. A 2018, 6, 18979-18986.

(19) Ma, S.; Deng, Y.; Xie, J.; He, K.; Liu, W.; Chen, X.; Li, X. Noble-metal-free $\mathrm{Ni}_{3} \mathrm{C}$ Cocatalysts Decorated CdS Nanosheets for High-efficiency Visible-light-driven Photocatalytic $\mathrm{H}_{2}$ Evolution. Appl. Catal., B 2018, 227, 218-228.

(20) Chen, L.; Huang, H.; Zheng, Y.; Sun, W.; Zhao, Y.; Francis, P. S.; Wang, $X$. Noble-Metal-free $\mathrm{Ni}_{3} \mathrm{~N} / \mathrm{g}-\mathrm{C}_{3} \mathrm{~N}_{4}$ Photocatalysts with Enhanced Hydrogen Production under Visible Light Irradiation. Dalton Trans. 2018, 47, 12188-12196.

(21) Chen, H.; Jiang, D.; Sun, Z.; Irfan, R. M.; Zhang, L.; Du, P. Cobalt Nitride as an Efficient Cocatalyst on CdS Nanorods for Enhanced Photocatalytic Hydrogen Production in Water. Catal. Sci. Technol. 2017, 7, 1515-1522. 
(22) Ma, B.; Liu, Y.; Li, J.; Lin, K.; Liu, W.; Zhan, H. $\mathrm{Mo}_{2} \mathrm{~N}$ : An Efficient Non-noble Metal Cocatalyst on CdS for Enhanced Photocatalytic $\mathrm{H}_{2}$ Evolution under Visible Light Irradiation. Int. J. Hydrogen Energy 2016, 41, 22009-22016.

(23) Ma, B.; Zhang, R.; Lin, K.; Liu, H.; Wang, X.; Liu, W.; Zhan, H. Large-scale Synthesis of Noble-metal-free Phosphide/CdS Composite Photocatalysts for Enhanced $\mathrm{H}_{2}$ Evolution under Visible Light Irradiation. Chin. J. Catal. 2018, 39, 527-533.

(24) Wang, J.; Wang, P.; Wang, C.; Ao, Y. In-situ Synthesis of Well Dispersed CoP Nanoparticles Modified CdS Nanorods Composite with Boosted Performance for Photocatalytic Hydrogen Evolution. Int. J. Hydrogen Energy 2018, 43, 14934-14943.

(25) Sun, Z.; Chen, H.; Huang, Q.; Du, P. Enhanced Photocatalytic Hydrogen Production in Water under Visible Light Using Noble Metal-free Ferrous Phosphide as an Active Cocatalyst. Catal. Sci. Technol. 2015, 5, 4964-4967.

(26) Cheng, H.; Lv, X.-J.; Cao, S.; Zhao, Z. Y.; Chen, Y.; Fu, W.-F. Robustly Photogenerating $\mathrm{H}_{2}$ in Water Using $\mathrm{FeP} / \mathrm{CdS}$ Catalyst under Solar Irradiation. Sci. Rep. 2016, 6, 19846.

(27) Sun, Z.; Yue, Q.; Li, J.; Xu, J.; Zheng, H.; Du, P. Copper Phosphide Modified Cadmium Sulfide Nanorods as a Novel $\mathrm{p}-\mathrm{n}$ Heterojunction for Highly Efficient Visible-light-driven Hydrogen Production in Water. J. Mater. Chem. A 2015, 3, 10243-10247.

(28) Sun, Z.; Zheng, H.; Li, J.; Du, P. Extraordinarily Efficient Photocatalytic Hydrogen Evolution in Water Using Semiconductor Nanorods Integrated with Crystalline $\mathrm{Ni}_{2} \mathrm{P}$ Cocatalysts. Energy Environ. Sci. 2015, 8, 2668-2676.

(29) Yue, Q.; Wan, Y.; Sun, Z.; Wu, X.; Yuan, Y.; Du, P. MoP is a Novel, Noble-metal-free Cocatalyst for Enhanced Photocatalytic Hydrogen Production from Water under Visible Light. J. Mater. Chem. A 2015, 3, 16941-16947.

(30) Zeng, D.; Ong, W.-J.; Zheng, H.; Wu, M.; Chen, Y.; Peng, D.L.; Han, M.-Y. $\mathrm{Ni}_{12} \mathrm{P}_{5}$ Nanoparticles Embedded into Porous g- $\mathrm{C}_{3} \mathrm{~N}_{4}$ Nanosheets as a Noble-metal-free Hetero-structure Photocatalyst for Efficient $\mathrm{H}_{2}$ Production under Visible Light. J. Mater. Chem. A 2017, 5, 16171-16178.

(31) Cheng, L.; Zhang, D.; Fan, J.; Liao, Y.; Xiang, Q. Metal Phosphide Modified $\mathrm{Cd}_{\mathrm{x}} \mathrm{Zn}_{1-\mathrm{x}} \mathrm{S}$ Solid Solutions as a Highly Active Visible-light Photocatalyst for Hydrogen Evolution. Appl. Catal., A 2020, 590, 117336

(32) Ding, S.; Cao, D.; Liu, D.; Lin, Y.; Wang, C.; Wu, C.; Zhou, Y.; Chen, S.; Song, L. Modulating Electronic Structure of Cobalt Phosphide Precatalysts via Dual-Metal Incorporation for Highly Efficient Overall Water Splitting. ACS Appl. Energy Mater. 2019, 2, 8022-8030.

(33) Dong, Y.; Kong, L.; Jiang, P.; Wang, G.; Zhao, N.; Zhang, H.; Tang, B. A General Strategy To Fabricate $\mathrm{Ni}_{\mathrm{x}} \mathrm{P}$ as Highly Efficient Cocatalyst via Photoreduction Deposition for Hydrogen Evolution. ACS Sustain. Chem. Eng. 2017, 5, 6845-6853.

(34) Chen, L.; Zhao, Y.; Yang, J.; Liu, D.; Wei, X.; Wang, X.; Zheng, Y. New Versatile Synthetic Route for the Preparation of Metal Phosphate Decorated Hydrogen Evolution Photocatalysts. Inorg. Chem. 2020, 59, 1566-1575.

(35) Moffat, J. B. Phosphates as Catalysts. Catal. Rev. 1978, 18, 199-258.

(36) Kanan, M. W.; Nocera, D. G. In Situ Formation of an OxygenEvolving Catalyst in Neutral Water Containing Phosphate and $\mathrm{Co}^{2+}$. Science 2008, 321, 1072-1075.

(37) Shi, G.; Shen, J. New Synthesis Method for Nickel Phosphide Nanoparticles: Solid Phase Reaction of Nickel Cations with Hypophosphites. J. Mater. Chem. 2009, 19, 2295-2297.

(38) Jin, K.; Park, J.; Lee, J.; Yang, K. D.; Pradhan, G. K.; Sim, U.; Jeong, D.; Jang, H. L.; Park, S.; Kim, D.; Sung, N.-E.; Kim, S. H.; Han, S.; Nam, K. T. Hydrated Manganese(II) Phosphate $\left(\mathrm{Mn}_{3}\left(\mathrm{PO}_{4}\right)_{2}\right.$. $\left.3 \mathrm{H}_{2} \mathrm{O}\right)$ as a Water Oxidation Catalyst. J. Am. Chem. Soc. 2014, 136, $7435-7443$

(39) Kim, H.; Park, J.; Park, I.; Jin, K.; Jerng, S. E.; Kim, S. H.; Nam, K. T.; Kang, K. Coordination Tuning of Cobalt Phosphates Towards Efficient Water Oxidation Catalyst. Nat. Commun. 2015, 6, 8253.
(40) Liu, P.; Rodriguez, J. A. Catalysts for Hydrogen Evolution from the $[\mathrm{NiFe}]$ Hydrogenase to the $\mathrm{Ni}_{2} \mathrm{P}$ (001) Surface: The Importance of Ensemble Effect. J. Am. Chem. Soc. 2005, 127, 14871-14878.

(41) Di, T.; Zhu, B.; Zhang, J.; Cheng, B.; Yu, J. Enhanced Photocatalytic $\mathrm{H}_{2}$ Production on CdS Nanorod Using Cobaltphosphate as Oxidation Cocatalyst. Appl. Surf. Sci. 2016, 389, 775782 .

(42) Yang, J.; Yan, H.; Wang, X.; Wen, F.; Wang, Z.; Fan, D.; Shi, J.; $\mathrm{Li}, \mathrm{C}$. Roles of Cocatalysts in Pt-PdS/CdS with Exceptionally High Quantum Efficiency for Photocatalytic Hydrogen Production. J. Catal. 2012, 290, 151-157.

(43) Wolff, C. M.; Frischmann, P. D.; Schulze, M.; Bohn, B. J.; Wein, R.; Livadas, P.; Carlson, M. T.; Jäckel, F.; Feldmann, J.; Würthner, F.; Stolarczyk, J. K. All-in-one Visible-light-driven Water Splitting by Combining Nanoparticulate and Molecular Co-catalysts on CdS Nanorods. Nat. Energy 2018, 3, 862-869.

(44) Wei, R.-B.; Huang, Z.-L.; Gu, G.-H.; Wang, Z.; Zeng, L.; Chen, Y.; Liu, Z.-Q. Dual-cocatalysts Decorated Rimous CdS Spheres Advancing Highly-efficient Visible-Light Photocatalytic Hydrogen Production. Appl. Catal., B 2018, 231, 101-107.

(45) Xing, M.; Qiu, B.; Du, M.; Zhu, Q.; Wang, L.; Zhang, J. Spatially Separated CdS Shells Exposed with Reduction Surfaces for Enhancing Photocatalytic Hydrogen Evolution. Adv. Funct. Mater. 2017, 27, 1702624.

(46) Li, Y.-D.; Liao, H.-W.; Ding, Y.; Qian, Y.-T.; Yang, L.; Zhou, G.-E. Nonaqueous Synthesis of CdS Nanorod Semiconductor. Chem. Mater. 1998, 10, 2301-2303.

(47) Chen, Y.-T.; Ding, J.-B.; Guo, Y.; Kong, L.-B.; Li, H.-L. A Facile Route to Preparation of CdS Nanorods. Mater. Chem. Phys. 2003, 77, 734-737.

(48) Yu, J.; Jin, J.; Cheng, B.; Jaroniec, M. A Noble Metal-free Reduced Graphene oxide-CdS Nanorod Composite for the Enhanced Visible-light Photocatalytic Reduction of $\mathrm{CO}_{2}$ to Solar Fuel. J. Mater. Chem. A 2014, 2, 3407-3416.

(49) Bai, Y.; Zhang, H.; Liu, L.; Xu, H.; Wang, Y. Tunable and Specific Formation of $\mathrm{C} @ \mathrm{NiCoP}$ Peapods with Enhanced HER Activity and Lithium Storage Performance. CHEM-EUR J. 2016, 22, $1021-1029$

(50) Chava, R. K.; Do, J. Y.; Kang, M. Fabrication of CdS- $\mathrm{Ag}_{3} \mathrm{PO}_{4}$ Heteronanostructures for Improved Visible Photocatalytic Hydrogen Evolution. J. Alloys Compd. 2017, 727, 86-93.

(51) Chen, D.; Kuang, Z.; Zhu, Q.; Du, Y.; Zhu, H. Synthesis and Characterization of CdS $/ \mathrm{BiPO}_{4}$ Heterojunction Photocatalyst. Mater. Res. Bull. 2015, 66, 262-267.

(52) Zheng, J.; Lei, Z. Incorporation of $\mathrm{CoO}$ Nanoparticles in 3D Marigold Flower-like Hierarchical Architecture $\mathrm{MnCo}_{2} \mathrm{O}_{4}$ for Highly Boosting Solar Light Photo-oxidation and Reduction Ability. Appl. Catal., B 2018, 237, 1-8.

(53) Xu, H.; Zhang, J.; Rehman, A. U.; Gong, L.; Kan, K.; Li, L.; Shi, K. Synthesis of NiO@CuO Nanocomposite as High-performance Gas Sensing Material for $\mathrm{NO}_{2}$ at Room Temperature. Appl. Surf. Sci. 2017, 412, 230-237.

(54) Zhang, W.; Mao, S.; Xu, J.; Xu, Q.; Zhang, M.; Zhou, J.; Song, L.; Guan, R.; Yue, L. Fabrication of Three-dimensional Hollow C@ CoO@graphene Composite Anode for Long-life Li-ion Batteries. Electrochim. Acta 2018, 291, 206-215.

(55) Yan, Z.; Wu, H.; Han, A.; Yu, X.; Du, P. Noble Metal-free Cobalt Oxide $\left(\mathrm{CoO}_{x}\right)$ Nanoparticles Loaded on Titanium Dioxide/ Cadmium Sulfide Composite for Enhanced Photocatalytic Hydrogen Production from Water. Int. J. Hydrogen Energy 2014, 39, 1335313360.

(56) Huang, J.; Sun, Y.; Zhang, Y.; Zou, G.; Yan, C.; Cong, S.; Lei, T.; Dai, X.; Guo, J.; Lu, R.; Li, Y.; Xiong, J. A New Member of Electrocatalysts Based on Nickel Metaphosphate Nanocrystals for Efficient Water Oxidation. Adv. Mater. 2018, 30, 1705045.

(57) Chang, J.; Lv, Q.; Li, G.; Ge, J.; Liu, C.; Xing, W. Core-shell Structured $\mathrm{Ni}_{12} \mathrm{P}_{5} / \mathrm{Ni}_{3}\left(\mathrm{PO}_{4}\right)_{2}$ Hollow Spheres as Difunctional and Efficient Electrocatalysts for Overall Water Electrolysis. Appl. Catal., B 2017, 204, 486-496. 
(58) Zhen, W.; Ning, X.; Yang, B.; Wu, Y.; Li, Z.; Lu, G. The Enhancement of CdS Photocatalytic Activity for Water Splitting via Anti-photocorrosion by Coating $\mathrm{Ni}_{2} \mathrm{P}$ Shell and Removing Nascent Formed Oxygen with Artificial Gill. Appl. Catal., B 2018, 221, 243257.

(59) Davis, A.; Huang, C. P. The Photocatalytic Oxidation of Sulfurcontaining Organic Compounds Using Cadmium Sulfide and the Effect on CdS Photocorrosion. Water Res. 1991, 25, 1273-1278.

(60) Oyama, S. T.; Gott, T.; Zhao, H.; Lee, Y.-K. Transition Metal Phosphide Hydroprocessing Catalysts: A review. Catal. Today 2009, 143, 94-107. 